\title{
Governing the tap: Special district governance and the new local politics of water.
}

M Mullin; The MIT Press, Cambridge, MA, US, 2009, 266 pages

How to implement a shift in water governance from traditional 'hard paths' characterised by large-scale infrastructure projects, to 'soft' options such as localised and regionalised water demand management, is a problem facing governments and water industries worldwide. As arid countries such as Australia and the United States try to find solutions to currently existing droughts, and 'wet' countries such as the United Kingdom contemplate a changing water future in the context of climate change, the types of institutional change that will be required to balance 'supply and demand' under conditions of complexity and uncertainty is becoming an increasingly salient issue.

In 'Governing the Tap' Megan Mullin offers a critique of changes to US water policy that is explicitly politically and institutionally focused. The book presents a US specific case study of the consequences of specialisation and fragmentation of water resource management for local policy making. It tracks the development of 'special districts' of water management public authorities that function as administrative bodies, but with a limited, water focused jurisdiction. This functional specialisation, Mullin argues, can create policy mechanisms that are more responsive to the complex problems at hand, but they can also create significant difficulties in governing cooperatively across jurisdictional boundaries. The book focuses on the influence of this specialisation on government decisions, the relationships between government and its' constituents under these arrangements, and the responsiveness of these various specialised systems to community interests. The broader question the book addresses, therefore, is how specialised governance can, and in what types of local contexts it fails to, effectively coordinate complex regional water-related policy challenges in the US.

Beyond the examples it provides, the book also offers a brief set of reflections about the institutional issues underpinning a shift to citizen participation in problem focused policy, and the issues of climate change. Special district governance appears to be beneficial in situations where: the problems at hand hold true for the majority of the population; where a better connection between policy and the public is required on issues that would usually struggle for attention in the political sphere; where policy problems are least severe; and 
where a balance is required amongst the multiple and competing visible demands about a particular (resource) conflict. An outcome of this analysis is that special district governance is an institutional strategy that provides opportunities for deliberation but not cooperative policy solutions, and reflects policy decisions based on 'majority rules' but not issues of equity or sustainability. Given the restricted settings in which fragmented specialisation is considered beneficial, I was left wondering how useful this concept really is in its ability to address the economic, social and environmental complexities of climate change.

The critical reflections on this were limited to a few pages in the final chapter. This served only to highlight a missed opportunity for the book to provide a genuinely critical political reflection on the ability of specialisation to address some of the most critical and complex challenges for governments around the world - water management under conditions of increasing scarcity and uncertainty. While I agree with Mullin that some form of localised effort is required to address (some) aspects of climate change, I disagree with the implied conclusion that special district governance is a flexible way to coordinate this. Taking a problem focus, the integration and coordination required at different scales to implement climate change mitigation and adaptation policies, is at odds with the circumstances in which Mullin's describes special district governance as being the most beneficial - where problems are bounded and fairly simple. Taking an institutional focus, fragmented specialisation may not be possible or in fact desirable in places other than the US. In countries characterised by privatisation and market environmentalism such as the UK, such a localised approach to water governance (bar widespread institutional and political reform), will never be possible. The political history of managing the Murray Darling Basin in Australia shows how the localisation of the politics of water resources is not always desirable. As this example shows, without the proper mechanisms in place to address social, environmental and economic equity issues that cross jurisdictional boundaries, such a localised approach can in fact result in severe mismanagement and irreversible environmental degradation.

Although there may be some examples of success of this approach in the US, such localised specialisation may not accurately address the uncertainties, complexities, and spatial inequities of water governance, particularly in the context of climate change. Given this, and 
the significant lack of engagement with political science and other disciplinary literature critiquing different forms of democracy and governance, the relevance of the book to EPC readers (other than those with a specific interest in US water policy) is fairly limited.

Alison L Browne, Lancaster Environment Centre, Lancaster University, Lancaster LA1 4YW, United Kingdom 